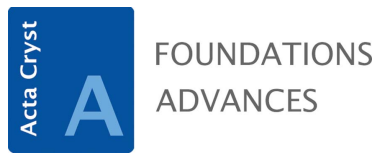

ISSN 2053-2733

\section{Symmetry Through the Eyes of the Old Masters. By Emil Makovicky. De Gruyter, 2016. Hardback, Pp. 240. Price EUR 99.95, USD 140.00, GBP 74.99. ISBN 978-3-11- 041705-0.}

\author{
Gregory McColm*
}

Department of Mathematics and Statistics, University of South Florida, 4202 E. Fowler Avenue, CMC342 Tampa, FL 33617, USA. *Correspondence e-mail: mccolm@usf.edu

Humans have long been fascinated by symmetry. The oldest known works of pure art designs carved into soft rocks up to 100000 years ago - are repeating patterns of high symmetry (Henshilwood et al., 2009), and both the archeological record and museums have numerous examples. Explanations for this fascination range from prehistoric encounters with crystals (Waterhouse, 1972) to our (possibly) greater ability to process our perceptions of symmetric patterns (Gombrich, 1979) to kaleidoscopic images observed by Stone Age people during sensory deprivation, exhaustion or neurological disorders, or psychedelic intoxication (Spivey, 2005). It is not surprising that symmetry has been a major part of the human enterprise. Yet while symmetry may pervade art, it is less visible in art history books. Janson \& Janson's (1962) magisterial 'History of Art', has almost no symmetry at all [although there is a brief and almost dismissive mention of '... a taste for symmetrical abstract patterns characteristic of Moslem art' (Janson \& Janson, 1962) in the largely architectural chapter on Islamic art].

Although aware of this lacking, Emil Makovicky presents his 'little book' not to address a deficiency but as a personal odyssey intended for 'entertainment and inspiration'. The author, armed with a camera, traveled the world and brings to fellow crystallographers accounts of and images of interesting and suggestive works of art - along with diagrams to assist their analysis. The book explores zero-, one- and two-dimensional symmetries in art from a crystallographic point of view, i.e. symmetry under group actions. (There are two chapters on aperiodic and fractal works towards the end of the book, but most of the book consists of planar geometric crystallography applied to art.) It is organized by crystallographic structure, beginning with representations of unequivocally finite structures, and proceeding to increasingly complex works.

The book starts with finite objects and friezes. There is no description of the point groups, so the discussion of finite structures is ad hoc. For example, in Fig. 1(a), a pillar of the Grand Mosque of Bursa has some Arabic calligraphy painted on it, with one side of the inscription being the mirror image of the other. Later in the text, there are a few more complex examples, such as the eightfold dihedral symmetry in Fig. 1(b).

Friezes are handled more formally, starting with diagrams of the seven frieze groups. Then it's on to Gothic vaults (which can be regarded as friezes with patterns consisting of the fluting), friezes spiraling up columns, friezes used as borders, and friezes wrapped around ceramics as in Fig. 2. The reader can compare the book's diagram for the frieze group $p 211$ (or $p 2$, although the text prefers $p 211$, and we will stick to the notation in the text) to the design on the vase, assuming that the pattern is solid black/hatched versus white.

Here, the book slips in color symmetries without much introduction. As artists colored periodic patterns in symmetry-breaking arrangements, color symmetries are necessary for a crystallographic analysis of their art. Very roughly, one has a crystallographic group for the underlying pattern, and then one permutes the colors. Space precludes further discussion of color symmetries here: for a technical description, see, e.g., Jaswon \& Rose (1983). ${ }^{2}$ Anyway, in Fig. 2, the point of the twofold rotation directly facing the viewer (or

\footnotetext{
${ }^{1}$ A new version - twice as long and now subtitled 'The Western Tradition' - was recently published by P. J. E. Davies, W. B. Denny, F. F. Hofrichter, J. Jacobs, D. L. Simon and A. S. Roberts.

${ }^{2}$ The usual procedure is to take the crystallographic group preserving the underlying pattern, and a subgroup preserving one of the colors, and the permutation of colors arises from the cosets of the subgroup.
} 


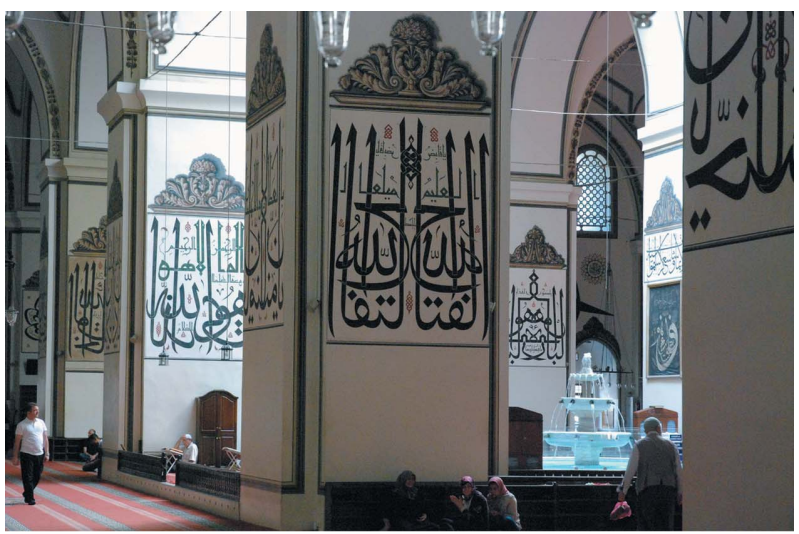

(a)

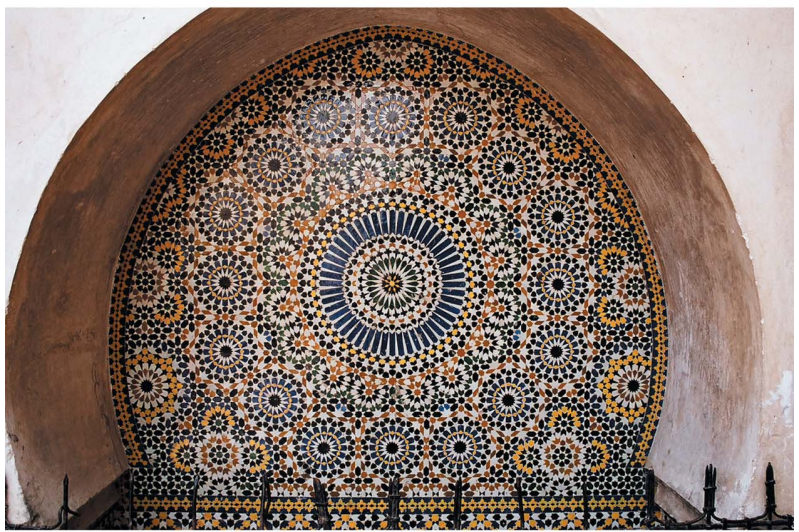

(b)

Figure 1

(a) 19th century calligraphy on a pillar of the 14th century Grand Mosque of Bursa, in Turkey (Makovicky, Fig. 1.15 on p. 11). (b) A fountain mosaic from Fez (Makovicky, Fig. 7.24 on p. 199).

either point of rotation to the left or right) rotates the solid black onto the hatched region, and vice versa. That color symmetry is denoted $p 2^{\prime} 11$, the ' marking that it is the twofold rotational symmetry that permutes the colors. This is a dichroic group (again, actually a crystallographic group and a permutation) as there are two colors. Later in the text, there are examples with multiple colors and hence polychroic groups.

The book deals with planes and layers more explicitly. For example, for Fig. 3, the reader is advised that the tracing of the pattern has a $p 6 \mathrm{~mm}$ symmetry. However, the coloring breaks the sixfold symmetry and we are left with a (colored) $\mathrm{c}^{\prime} \mathrm{mm}$ pattern. The diagrams for both groups are available, and the reader is invited to confirm this analysis. Much of the book consists of such examples, and the reader can either accept the analysis or verify it. Indeed, the energetic reader could treat much of the book as a sequence of exercises.

There is a chapter on polychroic patterns, but here there are no diagrams to assist the reader in what are now more complex analyses. This chapter is more challenging, and it reveals the variety of patterns artists have developed. And there are many variants, such as layers (appearing in screens or raised reliefs) and patterns consisting of one embedded within or on top of another, as in Fig. 4, in what is described as

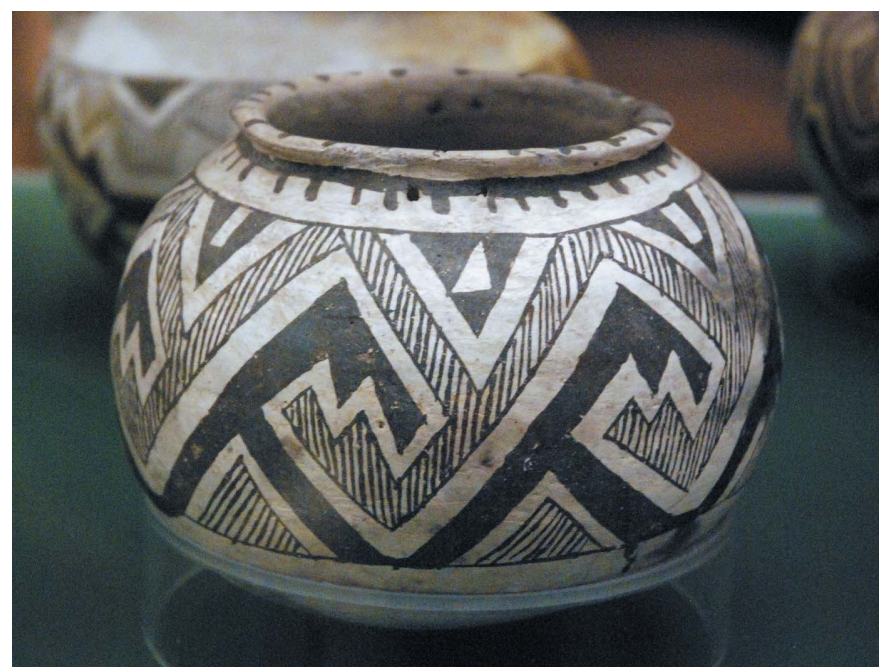

Figure 2

Pueblo vase from Arizona, decorated in a 12th century style (Makovicky, Fig. 1.45 on p. 31).

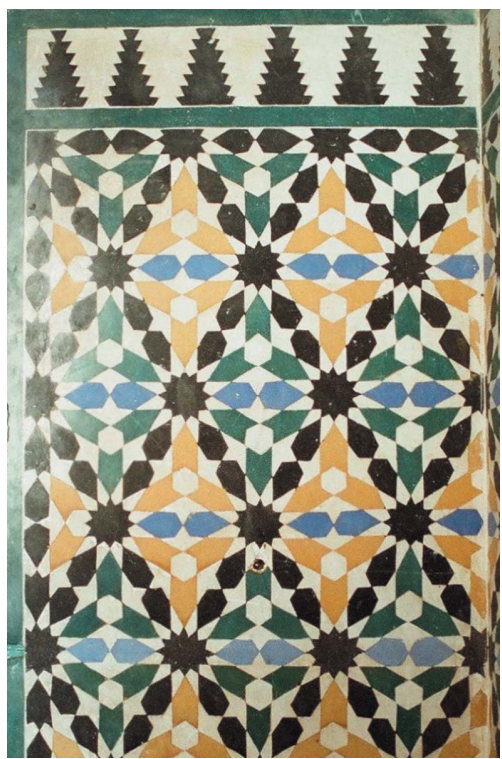

Figure 3

A pattern from the Alhambra, in Granada, Spain (Makovicky, Fig. 4.10 on p. 119).

an order-disorder pattern of thick-lined compartments filled with a sinuous curve winding through an (invisible) grid.

There is a crescendo running through the book, that of artists stacking patterns on top of each other. There are examples of twinning, homothety, hypersymmetry and other complications. Of hypersymmetry - a highly symmetric object embedded in a pattern of lower symmetry - he observes that although hypersymmetric objects in crystals tend to be distorted in situ, artists make images with undistorted hypersymmetric components. 'This does not exist in crystal structures...' (p. 149), a challenge to crystal engineers. Artists may be closer to mathematicians in that the primary question was whether the pattern itself can be realized. 


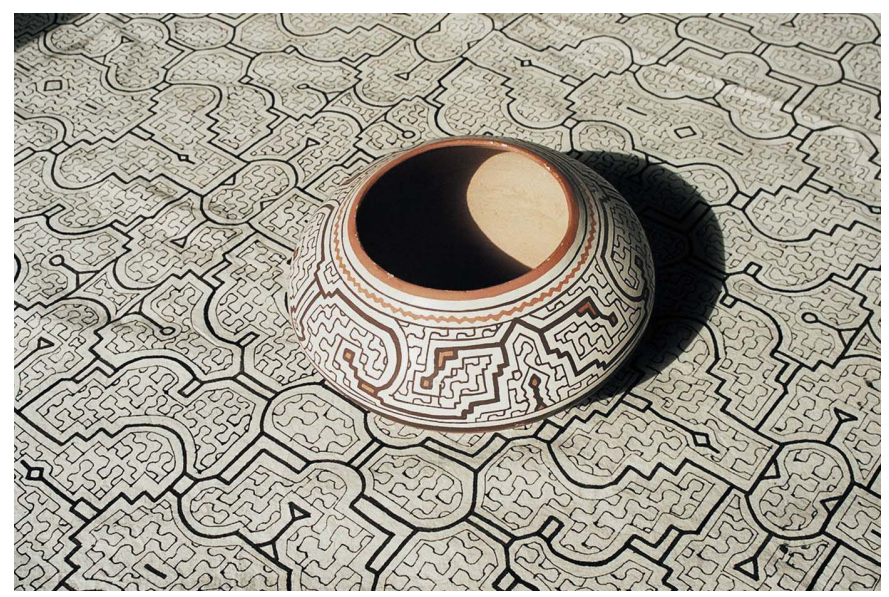

Figure 4

A pot and matching table cloth made by Shipobo Indians from Peru (Makovicky, Fig. 6.22 on p. 164).

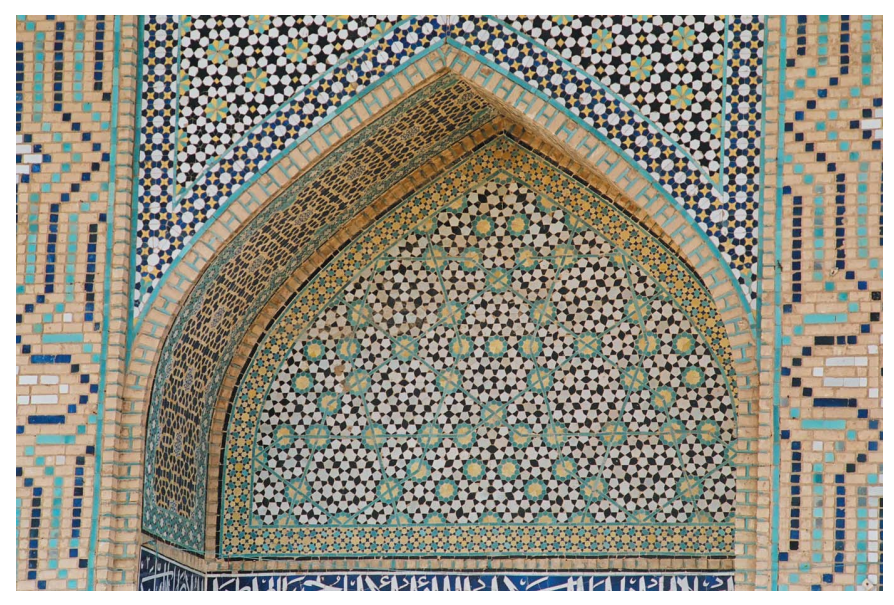

Figure 5

Upper archway of the Darb-e-Imam shrine in Isfahan, Iran (Makovicky, Fig. 7.4 on p. 183).

Artists have long created impressions of what Ernst Gombrich calls 'order' using aperiodic patterns, and this book makes two brief forays. One is a chapter on 'quasiperiodic' patterns, which consists largely of examples. As this chapter comes towards the end of the book, the examples are often sophisticated, like the blue lines of an apparent fragment of a $\mathrm{cmm}$ pattern imposed on fragments of quasiperiodic tilings of white and dark blue tiles in Fig. 5. This raises the question of how to interpret these patterns. The original artists created finite works (which they may or may not have regarded as indefinitely extendable) without the modern notions of crystallographic symmetry or quasiperiodicity. Makovicky asserts a 'real-world definition' for quasiperiodicity: 'for a sufficiently large patch' it has the correct local symmetries (p. 195).

The other foray is a chapter on fractal patterns. A fractal is actually a structure of fractional dimension $[e . g$. a coastline is a curve of 'Hausdorff dimension' between 1 and 2 (Mandelbrot, 1982)], but like most expositions, this book focuses on selfsimilar fractals, i.e. components with sub-components congruent to the larger component. The idea is so basic that artists

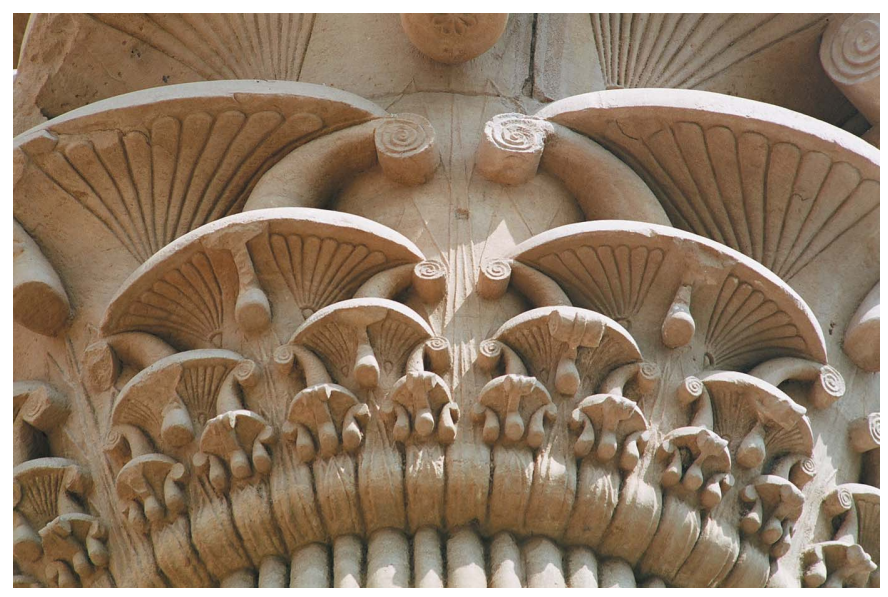

Figure 6

Capital of a column in the Philae temple complex on the Nile River (Makovicky, Fig. 8.6 on p. 206).

must have thought a lot about it, but the book has few examples of works with more than one or two iterations; Fig. 6 is unusual in having five iterations. Perhaps executing the idea in ceramic and stone was too challenging.

The book is organized by the complexity of the symmetries, but there are cultural threads that run through the text, for example, the flowery Iznik ceramics from 15th, 16th and 17th century Turkey, as in Fig. 7(a), and the stone Cosmatesque mosaics from 12th century Italy, as in Fig. 7(b). There is some native American and some East Asian art, but relatively little modern art; of course, a personal odyssey would result in such an idiosyncratic collection.

The book is a personal odyssey, but it may be more than that. First, what kind of art is it concerned with? In the Introduction, Makovicky distinguishes between representational and abstract art, writing that he will focus on the latter, and that '...geometric ornamental art has been kept for something lower in recent European history, being 'the applied art' of the artisans'. In his somewhat controversial 'Sense of Order', Gombrich described the abstractiondecoration-ornamentation issue as '.. a sensitive, not to say neurotic point in 20th century criticism' (Gombrich, 1979, p. 62) and wryly observed that 'one is reminded of Michelangelo, who rebuked a correspondent for addressing him as a sculptor'.

So the book is about art that people around the world have long appreciated, with the possible exception of a handful of modern critics. It is similar to catalogue-like art books already on the shelves; many of these consist of numerous analyses of many works of art, forming a sequence of variations on a theme. On the other hand, as a mathematically demanding book on mathematics in art, this book is similar to works by Ghyka (1946), Ivins Jr (1946), Pedoe (1976) and Skinner (2006), with an audience similar to the one interested in books by Conway et al. (2008) and Senechal \& Fleck (1988).

This 'little book' is many things, but one thing it is not is a view of symmetry 'through the eyes of the old masters'. The 


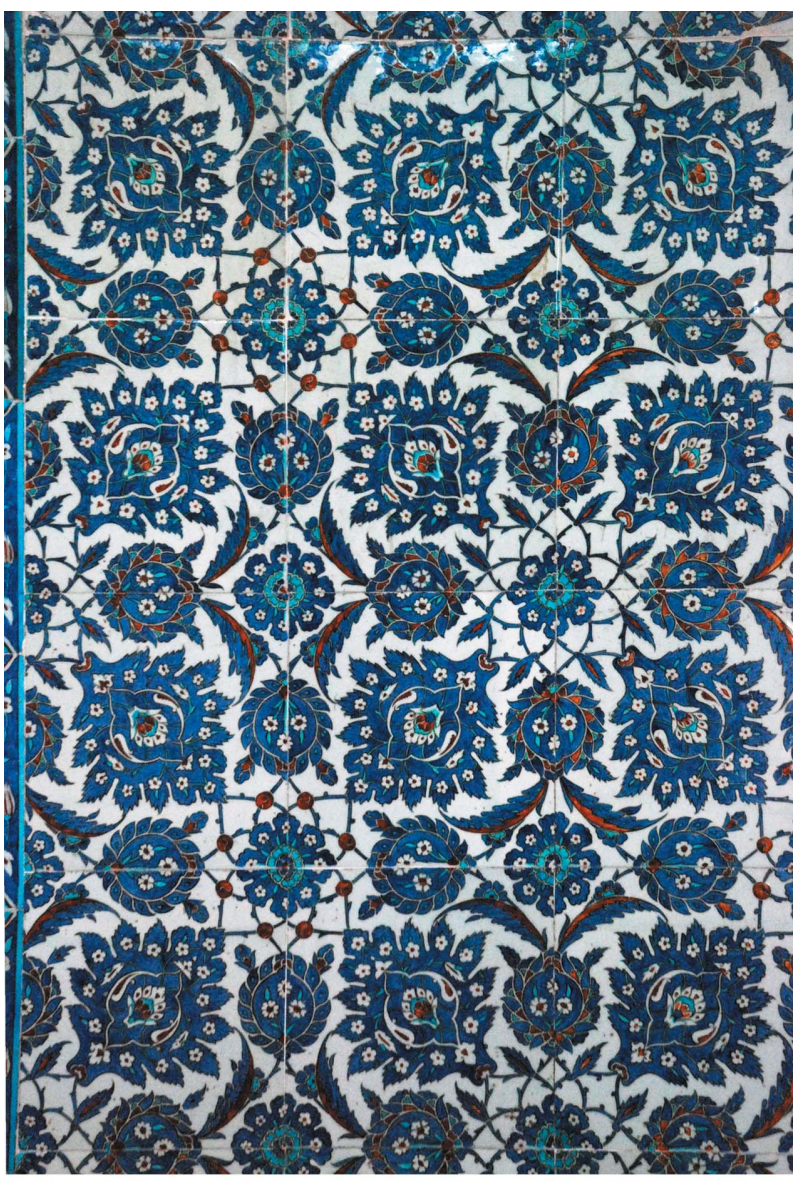

(a)

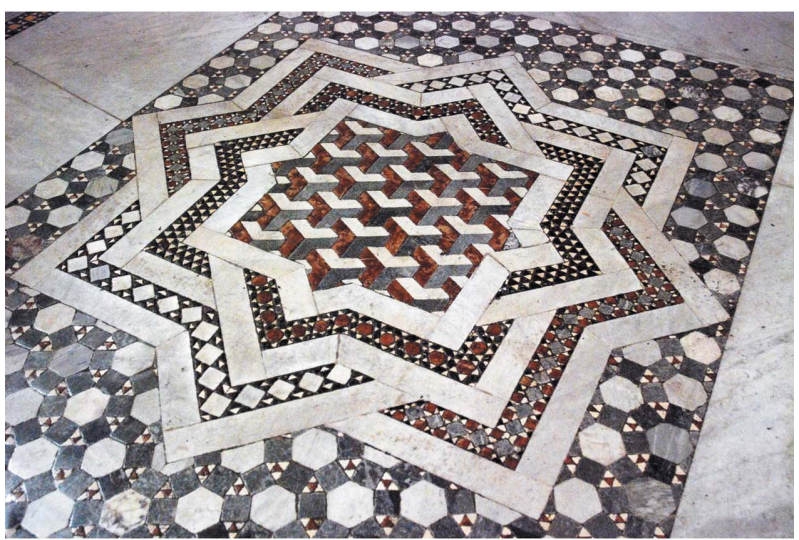

(b)

Figure 7

(a) An Iznik tiling; notice that a primitive unit cell spans four tiles (Makovicky, Fig. 2.31 on p. 56). (b) From the floor of the church of Santa Maria Maggiore, in Rome (Makovicky, Fig. 1.26 on p. 19).

book consists of analyses of art through the lens of groups of symmetries, which probably is not how the contemporaries saw it. Makovicky does warn that '... when comparing the concepts of the 14th and 20th centuries, we must keep in mind that the Hispano-Islamic artisans were artists, not theoretical scientists' (p. 180), but there is more to this than esthetics. Many of the tilings were made in the midst of alchemical, astrological, numerological and other enthusiasms that might articulate with some symmetry groups. In addition, there may be rules for assembling tiles that artists had found - through trial and error, or by some kind of analysis - that produced desirable results. In many cases, the thoughts, methods, motives, and even identities of the artists may be unknown, making it impossible to see through the eyes of those masters.

Their contemporaries may be another matter. Art is expensive to make, and the patrons who pay for the art often have prosaic motives. Art is fabricated within societies of particular preferences and restrictions, and there may be reasons why, for example, there are (apparently) more massive works of high symmetry in the Middle East than in Europe. And societies are not necessarily isolated in space and time, so influences can be traced along trade and tourist routes.

This is a little book, and space precluded introducing all this extraneous stuff, but it does suggest that this book might provide more than entertainment and inspiration. For one thing, this book does address the effect of the art on the viewer (or, at least on the author), often along the lines of Gombrich's chapter on 'The Analysis of Effects'. An art critic, art historian, or even a neurologist (they have got into the 'effect of art' game, too) might find Makovicky's analysis useful. In addition, there are a number of observations like '... a predilection of the old masters for the tetragonal group p422 ...' (p. 103). Of course, this is an ad hoc observation, and an art historian would want substantiation of this, but if it held up, why would this group be so popular? Would patterns of this symmetry be more readily or reliably assembled? Did the masters discover that these patterns made the sultan happier?

These are questions for the art historians and their retinue, and this leads to my primary lament. This is a book by a crystallographer for crystallographers. It was not written for an audience of scholars who would find it useful but who are not familiar with symmetry groups and are (all too often) weak in mathematics and geometry. It may be possible for this audience to use this book, as long as they keep resources like the Wikipedia page on Wallpaper Groups handy - and maybe find a friendly crystallographer. And it would be a good starting point for undergraduate and more advanced student projects. Considering that some scholars could be motivated to make the effort, this is a book that a strong liberal arts or fine arts institution would want in its library - and not as an online copy.

\section{Acknowledgements}

The author thanks Nigel Spivay for providing a useful reference and Professor Dr E. Makovicky for supplying original copies of the images.

\section{References}

Conway, J. H., Burgiel, H. \& Goodman-Strauss, C. (2008). The Symmetries of Things. A. K. Peters/CRC Press.

Gombrich, E. H. (1979). The Sense of Order: a Study in the Psychology of Decorative Art, chs. IV and V. Phaedon Press.

Ghyka, M. (1946). The Geometry of Art and Life. New York: Sheed and Ward. 


\section{book reviews}

Henshilwood, C. S., d'Errico, F. \& Watts, I. (2009). J. Human Evolution, 57, 27-47.

Ivins, M. I. Jr (1946). Art and Geometry: a Study in Space Intuitions. Harvard University Press.

Janson, H. W. \& Janson, D. S. (1962). History of Art: a Survey of the Major Visual Arts from the Dawn of History to the Present Day. Prentice-Hall and Harry N. Abrams.

Jaswon, M. A. \& Rose, M. A. (1983). Crystal Symmetry: Theory of Colour Crystallography. Ellis Horwood.
Mandelbrot, B. (1982). The Fractal Geometry of Nature. W. H. Freeman.

Pedoe, D. (1976). Geometry and the Visual Arts. Penguin.

Senechal, M. \& Fleck, G. (1988). Editors. Shaping Space: a Polyhedral Approach. Birkhäuser.

Skinner, S. (2006). Sacred Geometry: Deciphering the Code. Octopus. Spivey, N. (2005). How Art Made the World: a Journey to the Origins of Art, pp. 40-43. UK: BBC Books.

Waterhouse, W. C. (1972). Arch. Rational Mech. 9, 212-221. 